\title{
Combat exclusion RIP. Will patriarchy's demise follow?
}

\author{
Aaron Belkin
}

Palm Center, San Francisco, CA, USA

\begin{abstract}
During the first week of its new term in office, the administration of President Barack Obama not only surprised but also thrilled many progressives when the Pentagon rescinded its long-standing ban on women's involvement in combat. While the removal of combat exclusion will open up important professional opportunities for women serving in uniform, questions remain about whether patriarchy will continue to plague US military culture. Could formally allowing women to serve in combat diminish sexism or compel military men to treat women equally? Or is patriarchy likely to prevail within the ranks despite the expansion of women's professional roles? I suspect that patriarchy's entrenchment does not depend on whether women are present or even whether they hold high ranks or serve in prestigious combat roles. Rather, patriarchy reflects the gendered ways in which the armed forces socialize warriors (cf Belkin 2012). To the extent that Pentagon training methods remain the same, patriarchy will not disappear.

Experts on military culture have demonstrated that pervasive sexism can play out, even in integrated environments, via subtle but powerful micro-practices. When Stacie Furia completed Army boot camp for her doctoral research, she learned that calorie counts in military meals are tailored to the kind of (mostly men's) bodies that are presumed to be there. When women recruits did not finish their food, they were scolded for wasting it. When they completed their meals, they were disciplined for gaining weight (Furia 2010). Furia identified many such examples, and even though her superiors used politically correct language during training, she told me that
\end{abstract}

the rhetoric behind the rule not to behave in sexist ways was justified not by a sense that sexism is wrong, but that it might offend women in the ranks...[T]he implication was always that sexism should not and does not bother men, and that it isn't necessarily wrong, just in bad form to express in front of women.

Patriarchy's entrenchment is no accident, and reflects the gendered way in which the military teaches recruits how to behave violently. During training and beyond, the military removes service members' inhibitions against killing by brutalizing and feminizing them, and then inducing them to transfer feminization that has been instilled into them onto targets of violence that they imagine annihilating. As one male instructor explained to his all-male unit in the 1970's, 'Unless you women get with the program, straighten out the queers, and grow some balls of your own, you best give your soul to God, because your ass is mine and so is your mother's on visiting day.' Following the warning, the recruits knocked an under-performing unit member to the ground and kicked and punched him. He never returned to the unit. Surely, a subsequent step in this unit's training involved converting contempt for the feminine into disdain for the enemy. 
Would a drill instructor use such explicit language today given the repeal of 'don't ask, don't tell' and the elimination of the combat exclusion rule? Probably not. But even as the rhetoric of recruit training becomes more politically correct, the military likely will continue to train service members to feminize targets of violence. In turn, those moments when the troops internalize the gendering of the enemy are the same moments when opportunities for overcoming sexism and patriarchy disappear. It is not realistic for male service members, trained to feminize those who they might have to kill, to treat women equally in other contexts.

To be sure, women must be allowed to take on new roles and responsibilities that enable them to advance to the highest echelons of the armed forces. But patriarchal aspects of military culture are not about whether women are allowed to engage in combat, but rather about how the military manipulates ideas about gender as it teaches men and women how to kill.

\section{Notes on contributor}

Aaron Belkin is professor of political science at San Francisco State University, director of the Palm Center, and author, most recently, of Bring Me Men: Military Masculinity and the Benign Facade of American Empire, 1898-2001, and How We Won: Progressive Lessons from the Repeal of 'Don't Ask, Don't Tell.'

\section{References}

Belkin, A. 2012. Bring Me Men: Military Masculinity and the Benign Façade of American Empire, 1898-2001. New York: Columbia University Press.

Furia, S. R. 2010. "Navigating the Boundaries: Army Women in Training." In Research in the Sociology of Work, edited by C. Williams and K. D. Bingley, 107-126. Bingley: Emerald Group Publishing Limited. 